\title{
Branched-Chain Amino Acids and Risk of Breast Cancer
}

\author{
Oana A. Zeleznik (D), PhD, ${ }^{1, *}$ Raji Balasubramanian (D), ScD, ${ }^{2}$ Yumeng Ren (D), MS, ${ }^{1,3}$ Deirdre K. Tobias (D), ScD, ${ }^{4,6}$ \\ Bernard A. Rosner (D) PhD, ${ }^{1}$ Cheng Peng (D), ScD, ${ }^{1}$ Alaina M. Bever (D), BS, ${ }^{1,3}$ Lisa Frueh (D), BA, ${ }^{1}$ \\ Sarah Jeanfavre, MS, ${ }^{5}$ Julian Avila-Pacheco, PhD, ${ }^{5}$ Clary B. Clish (D, PhD, ${ }^{5}$ Samia Mora (D, MD, ${ }^{2}$ \\ Frank B. Hu (D), $\mathrm{PhD},{ }^{6}$ A. Heather Eliassen (D), ScD, ${ }^{1,3}$
}

\begin{abstract}
${ }^{1}$ Channing Division of Network Medicine, Brigham and Women's Hospital and Harvard Medical School, Boston, MA, USA; ${ }^{2}$ Department of Biostatistics and Epidemiology, University of Massachusetts-Amherst, Amherst, MA, USA; ${ }^{3}$ Department of Epidemiology, Harvard T.H. Chan School of Public Health, Boston, MA, USA; ${ }^{4}$ Division of Preventive Medicine, Department of Medicine, Brigham and Women's Hospital and Harvard Medical School, Boston, MA, USA; ${ }^{5}$ Broad Institute of Massachusetts Institute of Technology and Harvard, Cambridge, MA, USA; and ${ }^{6}$ Department of Nutrition, Harvard T.H. Chan School of Public Health, Boston, MA, USA

*Correspondence to: Oana A. Zeleznik, PhD, Channing Division of Network Medicine, Brigham and Women's Hospital,181 Longwood Ave, Boston, MA 02115, USA (e-mail: ozeleznik@bwh.harvard.edu).
\end{abstract}

\begin{abstract}
Background: Circulating branched-chain amino acid (BCAA) levels reflect metabolic health and dietary intake. However, associations with breast cancer are unclear. Methods: We evaluated circulating BCAA levels and breast cancer risk within the Nurses' Health Study (NHS) and NHSII (1997 cases and 1997 controls). A total of 592 NHS women donated 2 blood samples 10 years apart. We estimated odds ratios (ORs) and 95\% confidence intervals (CIs) of breast cancer risk in multivariable logistic regression models. We conducted an external validation in 1765 cases in the Women's Health Study (WHS). All statistical tests were 2-sided. Results: Among NHSII participants (predominantly premenopausal at blood collection), elevated circulating BCAA levels were associated with lower breast cancer risk (eg, isoleucine highest vs lowest quartile, multivariable $\mathrm{OR}=0.86,95 \% \mathrm{CI}=0.65$ to $1.13, P_{\text {trend }}=.20$ ), with statistically significant linear trends among fasting samples (eg, isoleucine $\mathrm{OR}=0.74,95 \% \mathrm{CI}=0.53$ to $\left.1.05, P_{\text {trend }}=.05\right)$. In contrast, among postmenopausal women, proximate measures $(<10$ years from blood draw) were associated with increased breast cancer risk (eg, isoleucine $\mathrm{OR}=1.63,95 \% \mathrm{CI}=1.12$ to 2.39 , $P_{\text {trend }}=$ $.01)$, with stronger associations among fasting samples $\left(\mathrm{OR}=1.73,95 \% \mathrm{CI}=1.15\right.$ to $\left.2.61, \mathrm{P}_{\text {trend }}=.01\right)$. Distant measures $(10-20$ years since blood draw) were not associated with risk. In the WHS, a positive association was observed for distant measures of leucine among postmenopausal women $\left(\mathrm{OR}=1.23,95 \% \mathrm{CI}=0.96\right.$ to $\left.1.58, P_{\text {trend }}=.04\right)$. Conclusions: No statistically significant associations between BCAA levels and breast cancer risk were consistent across NHS and WHS or NHSII and WHS. Elevated circulating BCAA levels were associated with lower breast cancer risk among predominantly premenopausal NHSII women and higher risk among postmenopausal women in NHS but not in the WHS. Additional studies are needed to understand this complex relationship.
\end{abstract}

Breast cancer is the most common malignancy in women, with more than 250000 diagnoses annually in the United States (1). Epidemiologic studies have identified modifiable risk factors, including increased body mass index (BMI) and low physical activity in postmenopausal women (2). However, BMI is inversely associated with premenopausal breast cancer (3). These findings indicate that poor metabolic health may be associated with breast cancer, although mechanisms and explanations for the variation by menopausal status remain unclear.

The branched-chain amino acids (BCAA) leucine, valine, and isoleucine are essential amino acids obtained from diet and are important metabolites involved in cell-signaling pathways and muscle protein synthesis (4). Elevated plasma BCAA concentrations are strongly positively correlated with BMI and insulin resistance and are a marker of dysfunctional metabolism (5). Whether elevated BCAAs are associated with breast cancer incidence, and whether this differs by menopausal status, remains unknown.

To date, few studies have evaluated BCAAs with breast cancer risk, with inconsistent results, and only 1 assessed menopausal status (6-10). We conducted a nested case-control study within the Nurses' Health Study (NHS) and NHSII to investigate the association between plasma BCAA levels and breast cancer risk. In secondary analyses, we conducted a validation analysis in the Women's Health Study (WHS). 


\section{Methods}

\section{Study Population}

In 1976, 121701 female registered nurses aged 30-55 years enrolled in the NHS with the return of a mailed questionnaire (11). Participants have been followed biennially with questionnaires on reproductive history, lifestyle factors, diet, medication use, and new disease diagnoses. The NHSII began in 1989 with 116429 female registered nurses aged 25-42 years, with biennial follow-up using similar questionnaires as NHS.

In 1989-1990, 32826 NHS participants aged 43-69 years contributed blood samples, as previously described (12). In 20002002, 18473 of these women aged 53-80 years donated a second sample using a similar protocol. In the NHSII, 29611 women aged 32-54 years donated blood samples in 1996-1999. Followup in the blood subcohorts is high (NHS 97\% in 2010; NHSII 96\% in 2011). Detailed information on sample collection, covariates, and selection of cases and controls in NHS/NHSII and WHS is in the Supplementary Methods (available online).

The study protocol was approved by the institutional review boards of the Brigham and Women's Hospital and Harvard T.H. Chan School of Public Health and those of participating registries as required. The return of the self-administered questionnaire and blood sample was considered to imply consent.

\section{Laboratory Assays}

In the NHS and NHSII, BCAAs were assayed through a metabolomic profiling platform at the Broad Institute using a liquid chromatography mass spectrometry method designed to measure polar metabolites such as amino acids, amino acid derivatives, dipeptides, and other cationic metabolites (13-15). BCAAs were identified by matching measured chromatographic retention times and mass-to-charge ratios with authentic reference standards. The relative abundance of each BCAA was determined by integration of liquid chromatography tandem mass spectrometry peak areas, which are unitless numbers directly proportional to metabolite concentrations. A detailed description of the laboratory assays used to measure BCAAs, gene expression, estradiol, and C-peptide is included in the Supplementary Methods (available online).

\section{Statistical Analysis}

BCAA values were log transformed and standardized (mean $=0$; $\mathrm{SD}=1$ ) within each cohort and blood collection separately (based on the distribution in all samples, including both cases and controls). To estimate the association between BCAAs as a group and risk of breast cancer, we calculated the sum of all 3 BCAAs (total BCAAs) and considered it an exposure in our analyses.

We estimated within-person stability over 10 years by calculating intra-class correlation (ICC) using mixed liner models among participants who donated 2 blood samples 10 years apart.

We used linear regression models of probit-transformed circulating BCAA levels to estimate beta coefficients for potential predictors, such as dietary BCAA intake, fasting status, BMI, age, and other lifestyle factors among NHS and NHSII $(\mathrm{N}=9112)$ women.

Conditional logistic regression was used to evaluate the associations between BCAAs and breast cancer risk in each cohort separately. We estimated odds ratios (ORs) and 95\% confidence intervals (CIs) across quartiles (based on the control distribution) of BCAA levels and used quartile medians (based on the control distribution) to estimate linear trend $P$ values. In a sensitivity analysis, we compared conditional with unconditional logistic regression adjusted for matching factors and obtained similar results (data not shown). Thus, we used unconditional logistic regression in analyses stratified by BMI and estrogen receptor (ER) status.

In multivariable models, we adjusted for established breast cancer risk factors: BMI at age 18 years, weight change from age 18 years to blood draw, age at menarche, parity and age at first birth, family history of breast cancer, history of benign breast disease, physical activity, alcohol consumption, exogenous hormone use, and breastfeeding history. In a separate analysis among NHS participants, we cross-classified participants based on the median BCAA levels among controls at the 2 blood collections. In the WHS, we used Cox proportional hazards regression models with follow-up from the date of random assignment to date of first invasive cancer diagnosis, death, or December 31, 2018. The Cox proportional hazard assumption was tested through the inclusion of a cross product term for BCAA and time (years from baseline blood draw); this assumption was met, with no indication for a violation. We assessed heterogeneity between NHS and WHS, and between NHSII and WHS using the DerSimonian-Laird estimator (16), and based on these findings, meta-analyzed individual cohort results using a fixed or random effects approach.

We used Correlation Adjusted Mean Rank analysis on tumor gene expression data to explore functional enrichment of biological pathways associated with BCAAs (Supplementary Methods, available online) (17).

We conducted sensitivity analyses restricting to fasting samples ( $>8$ hours since last meal), restricting to premenopausal or postmenopausal women at blood collection, adjusting for BMI at the time of the blood collection instead of BMI at age 18 years and weight change between age 18 years and blood collection, and adjusting for plasma C-peptide (a marker of insulin production) and estradiol in individual models.

All statistical tests were 2-sided, and a $P$ value of less than .05 was considered statistically significant. Analyses were conducted using $\mathrm{R}$ version 3.6.0, $\mathrm{R}$ version 3.1.4 and SAS Version 9.3 software (SAS Institute, Cary, NC).

\section{Results}

In total, 1997 matched case-control pairs were included (Table 1; Figure 1). NHSII women (1057 cases, 1057 controls) were predominantly premenopausal $(80.2 \%$ cases, $79.7 \%$ controls) at blood collection (mean age $=45$ years). NHS participants included 940 cases and their matched controls with a blood sample during the first collection (1989-1990, distant); of these, 592 cases and their matched controls had a second sample (20002002, proximate). NHS participants were predominantly postmenopausal (first collection $=61.9 \%$; second collection $=98.1 \%$ ), with a mean age of 55 years at distant and 66 years at proximate collections. Mean times between blood collection and diagnosis were: NHSII, 8 years; NHS distant measure, 15 years; and NHS proximate measure, 4 years.

WHS ( $\mathrm{N}=1765$ cases) included $54.0 \%$ postmenopausal and $46.0 \%$ premenopausal women at blood collection. Mean time to diagnosis was similar to NHS and NHSII: 6 years for postmenopausal cases with proximate samples, 16 years for postmenopausal cases with distant samples, and 5 years for premenopausal 
Table 1. Characteristics of breast cancer cases and matched controls in the NHSs

\begin{tabular}{|c|c|c|c|c|c|c|}
\hline \multirow[b]{2}{*}{ Participant characteristics } & \multicolumn{2}{|c|}{ NHSII } & \multicolumn{2}{|c|}{ NHS distant collection ${ }^{a}$} & \multicolumn{2}{|c|}{ NHS proximate collection ${ }^{\mathrm{b}}$} \\
\hline & $\begin{array}{c}\text { Cases } \\
(\mathrm{N}=1057)\end{array}$ & $\begin{array}{l}\text { Controls } \\
(\mathrm{N}=1057)\end{array}$ & $\begin{array}{l}\text { Cases } \\
(\mathrm{N}=940)\end{array}$ & $\begin{array}{l}\text { Controls } \\
(\mathrm{N}=940)\end{array}$ & $\begin{array}{l}\text { Cases } \\
(\mathrm{N}=592)\end{array}$ & $\begin{array}{l}\text { Controls } \\
(\mathrm{N}=592)\end{array}$ \\
\hline Mean age at blood collection ${ }^{c}(S D), y$ & $44.7(4.5)$ & $44.8(4.4)$ & $55.5(6.9)$ & $55.6(6.9)$ & $66.4(6.9)$ & $66.5(6.8)$ \\
\hline Mean time between blood collection and diagnosis (SD), y & $8.0(4.4)$ & - & $14.6(3.0)$ & - & $4.0(2.6)$ & - \\
\hline Mean age at menarche (SD), y & $12.4(1.3)$ & $12.5(1.4)$ & $12.5(1.4)$ & $12.6(1.4)$ & $12.5(1.4)$ & $12.6(1.4)$ \\
\hline \multicolumn{7}{|l|}{ Parity and age at first birth, \% } \\
\hline Nulliparous & 21.1 & 18.4 & 9.6 & 8.0 & 8.6 & 5.9 \\
\hline $1-2$ children $<25$ y & 14.7 & 15.9 & 13.5 & 14.1 & 13.0 & 15.9 \\
\hline $1-2$ children $\geq 25$ y & 39.2 & 34.9 & 20.1 & 20.6 & 20.4 & 19.3 \\
\hline $3+$ children $<25 y$ & 11.3 & 16.6 & 35.5 & 35.5 & 36.5 & 38.3 \\
\hline $3+$ children $\geq 25 y$ & 13.8 & 14.2 & 21.3 & 21.7 & 21.5 & 20.6 \\
\hline Family history of breast cancer, $\%$ & 17.4 & 10.8 & 14.6 & 10.7 & 22.5 & 14.2 \\
\hline Personal history of benign breast disease, $\%$ & 22.1 & 15.6 & 45.9 & 37.8 & 62.5 & 54.7 \\
\hline BMI at age $18, \mathrm{~kg} / \mathrm{m}^{2}$ & $20.8(2.9)$ & $21.1(3.1)$ & $21.1(2.7)$ & $21.3(3.0)$ & $21.0(2.6)$ & $21.3(3.0)$ \\
\hline $\begin{array}{l}\text { Mean weight change between age } 18 \mathrm{y} \text { and } \\
\text { blood collection (SD), kg }\end{array}$ & $11.6(12.0)$ & $12.6(13.2)$ & $12.3(10.9)$ & $10.6(11.2)$ & $15.5(12.7)$ & $13.8(12.7)$ \\
\hline Mean physical activity (SD), MET-h/wk & $18.0(15.3)$ & $18.1(15.5)$ & $15.4(18.8)$ & $15.9(17.6)$ & $17.7(14.8)$ & $19.0(17.7)$ \\
\hline Mean alcohol consumption (SD), g/d & $3.8(6.9)$ & $3.3(5.6)$ & $6.9(9.9)$ & $5.9(8.2)$ & $6.7(9.2)$ & $5.8(7.7)$ \\
\hline Past/current exogenous hormone use ${ }^{\mathrm{c}, \mathrm{d}}, \%$ & 86.3 & 86.7 & 68.1 & 68.2 & 80.6 & 81.2 \\
\hline Ever breastfed, \% & 63.1 & 65.0 & 64.3 & 62.0 & 67.4 & 64.4 \\
\hline \multicolumn{7}{|l|}{ Menopausal status at blood collection ${ }^{c}, \%$} \\
\hline Premenopausal & 80.2 & 79.7 & 25.4 & 25.5 & 0.5 & 0.8 \\
\hline Postmenopausal & 12.7 & 13.1 & 61.9 & 61.9 & 98.1 & 98.1 \\
\hline Unknown & 7.1 & 7.3 & 12.7 & 12.6 & 1.4 & 1.0 \\
\hline \multicolumn{7}{|l|}{ Menopausal status at diagnosis ${ }^{c}, \%$} \\
\hline Premenopausal & 42.0 & 42.2 & 1.3 & 1.3 & 1.4 & 1.0 \\
\hline Postmenopausal & 46.4 & 47.1 & 97.3 & 98.1 & 97.8 & 98.3 \\
\hline Unknown & 11.6 & 10.7 & 1.4 & 0.6 & 0.8 & 0.7 \\
\hline Fasting ( $>8 \mathrm{~h}$ ) at blood collection ${ }^{\mathrm{c}}, \%$ & 68.7 & 74.7 & 66.6 & 72.7 & 87.0 & 92.4 \\
\hline Caucasianc ${ }^{c}, \%$ & 97.2 & 98.4 & 98.3 & 98.8 & 98.6 & 99.5 \\
\hline
\end{tabular}

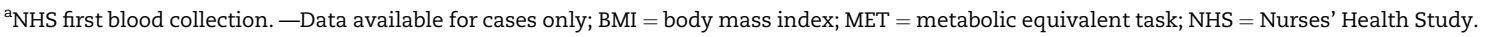

${ }^{\mathrm{b}} \mathrm{NHS}$ second blood collection.

${ }^{\mathrm{c}}$ Matching factor.

${ }^{\mathrm{d}}$ Oral contraceptive or menopausal hormone therapy.

women at blood collection. Demographics were similar to NHS; exceptions included lower family history of breast cancer (Table 2).

BCAA levels were reasonably stable over 10 years among women with repeated measures $(\mathrm{N}=592$; ICC isoleucine $=0.45$, leucine $=0.44$, valine $=0.48$ ). Dietary intake of BCAAs, BMI, and nonfasting blood collection were statistically significantly positively associated with BCAA levels, and Asian Americans had higher levels than Caucasians (Table 3). Alcohol consumption and diet quality were statistically significantly inversely associated with BCAA levels.

Among predominantly premenopausal women at blood collection (1057 cases), BCAAs were inversely associated with risk of breast cancer (simple model) (eg, isoleucine highest vs lowest quartile $\mathrm{OR}=0.76,95 \% \mathrm{CI}=0.59$ to $0.99, P_{\text {trend }}=.02$; Table 4 ), with statistically significant linear trends. These associations were attenuated and no longer statistically significant with adjustment for breast cancer risk factors (eg, isoleucine highest vs lowest quartile $\mathrm{OR}=0.86,95 \% \mathrm{CI}=0.65$ to $1.13, P_{\text {trend }}=.20$ ). Associations were similar for leucine $(\mathrm{OR}=0.77,95 \% \mathrm{CI}=0.58$ to $1.01)$ and valine $(\mathrm{OR}=0.82,95 \% \mathrm{CI}=0.62$ to 1.08$)$. We observed stronger associations among fasting samples only (715 cases; top vs bottom quartile $\mathrm{OR}=$ isoleucine $=0.74,95 \% \mathrm{CI}=0.53$ to $1.05, P_{\text {trend }}=.05$; leucine $=0.66,95 \% \mathrm{CI}=0.47$ to $0.94, P_{\text {trend }}=.04$; valine $=0.74,95 \% \mathrm{CI}=0.53$ to $\left.1.04, P_{\text {trend }}=.08\right)$. Associations with total BCAAs followed a similar pattern but were attenuated compared with individual BCAAs (OR $=0.79,95 \% \mathrm{CI}=0.56$ to $\left.1.11, P_{\text {trend }}=.12\right)$. We observed similar associations when we further restricted to premenopausal women at blood collection (541 cases; OR: leucine $=0.61,95 \% \mathrm{CI}=0.40$ to $0.92, P_{\text {trend }}=.04$; data not shown) and when we restricted to women premenopausal at diagnosis (255 cases; data not shown).

Among postmenopausal women, we observed positive associations between distant (10-20 years before diagnosis; 940 cases) measures of isoleucine and leucine and breast cancer risk in the simple model; however, these were attenuated and no longer statistically significant with multivariable adjustment (eg, isoleucine $\mathrm{OR}=1.15,95 \% \mathrm{CI}=0.87$ to $1.52, P_{\text {trend }}=.35$ ). BCAAs from proximate samples (592 cases) were positively associated with breast cancer risk and similar between the simple and multivariable models (eg, isoleucine multivariable $\mathrm{OR}=1.63,95 \% \mathrm{CI}=1.12$ to $\left.2.39, \mathrm{P}_{\text {trend }}=.01\right)$. Weaker associations were observed for leucine $(\mathrm{OR}=1.26,95 \% \mathrm{CI}=0.87$ to 1.83 , $\left.P_{\text {trend }}=.17\right)$ and valine $\left(\mathrm{OR}=1.34,95 \% \mathrm{CI}=0.93\right.$ to $1.94, P_{\text {trend }}=$ .12). Associations were stronger, with statistically significant linear trends (except for leucine), when restricted to fasting samples (513 cases; isoleucine $\mathrm{OR}=1.73,95 \% \mathrm{CI}=1.15$ to 2.61 , $P_{\text {trend }}=.01$; leucine $\mathrm{OR}=1.31,95 \% \mathrm{CI}=0.87$ to $1.98, P_{\text {trend }}=.12$; valine $\mathrm{OR}=1.64,95 \% \mathrm{CI}=1.11$ to $\left.2.43, P_{\text {trend }}=.04\right)$. Association with total BCAAs followed the same pattern as individual 
A Age distribution

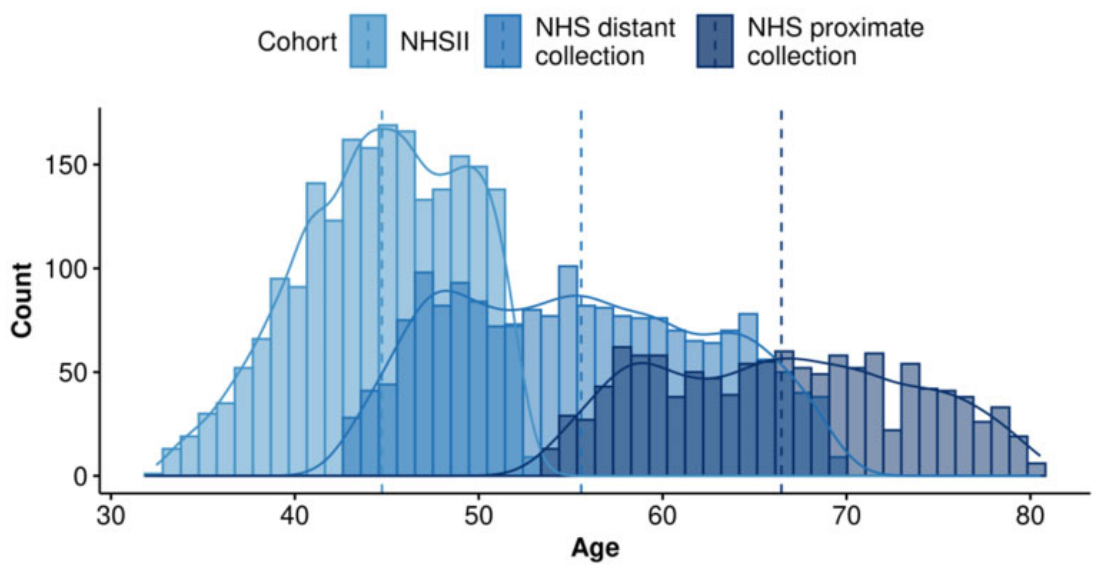

B Menopausal status distribution

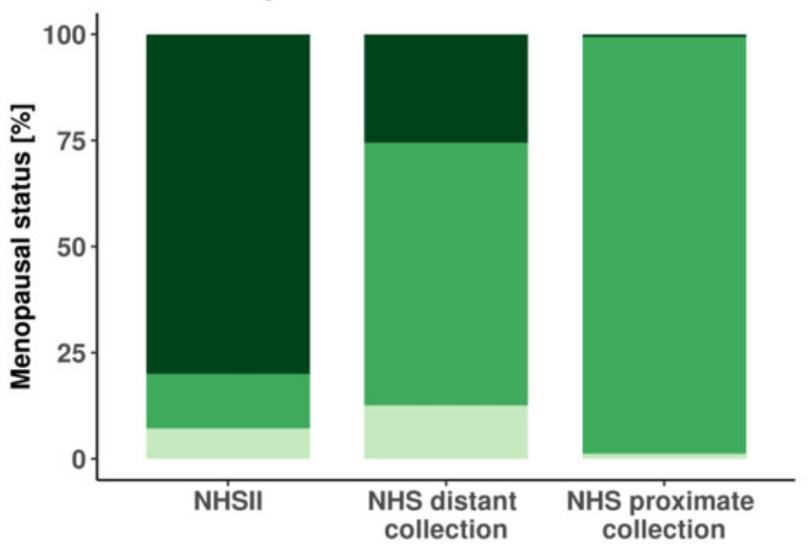

Menopausal status

Premenopausal

Postmenopausal Unknwon

Figure 1. Age and menopausal status distribution at blood collection. Panel A shows the age distribution in the 3 datasets: Nurses' Health Study (NHS) distant collection in blue, NHS proximate collection in dark blue, and NHSII in light blue. Median age is marked by vertical dashed lines. Panel B shows distribution of menopausal status in the 3 datasets: premenopausal status is shown in dark green, postmenopausal status is shown in green, and unknown status is shown in light green.

BCAAs (eg, fasting samples, multivariable OR $=1.56,95 \% \mathrm{CI}=$ 1.04 to $2.34, P_{\text {trend }}=.06$ ). A statistically significant interaction with menopausal status at blood collection $(P<.004)$ was observed when we pooled NHSII and NHS women with proximate measures in the multivariable model.

Individual and total BCAAs were not associated with breast cancer risk among WHS premenopausal at blood collection (763 cases) or postmenopausal women with distant (515 cases) or proximate (487 cases) blood collections. For example, among postmenopausal women with proximate measures, the multivariable odds ratio for isoleucine was $0.97(95 \% \mathrm{CI}=0.75$ to 1.26 , $\left.P_{\text {trend }}=.85\right)$ (Table 5). A suggestive positive association was observed for leucine and risk among postmenopausal women with distant sample collection (multivariable $\mathrm{OR}=1.23,95 \% \mathrm{CI}$ $=0.96$ to $\left.1.58, P_{\text {trend }}=.04\right)$. Results were similar when restricted to fasting samples $(70.1 \%-73.8 \%)$. There were too few women premenopausal at diagnosis to examine these associations in WHS $(\mathrm{n}=36)$. We did not observe statistically significant heterogeneity between the cohorts except for isoleucine among postmenopausal women with proximate blood collection. We observed no statistically significant associations between individual and total BCAA levels and breast cancer risk when metaanalyzing NHS and WHS or NHSII and WHS results.

Results among NHS and NHSII women did not change in sensitivity analyses (data not shown), among pre- and postmenopausal women separately, in which we adjusted for BMI at blood collection instead of BMI at age 18 years and weight change between age 18 years and blood collection. Among women with previously measured plasma C-peptide $(n=579$ NHSII, 244 NHS proximate, 407 NHS distant) and estradiol ( $\mathrm{n}=558$ luteal and 532 follicular NHSII, 234 NHS proximate, 288 NHS distant), the associations with BCAAs were unchanged with additional adjustment for C-peptide or estradiol levels.

No associations were observed for individual and total BCAAs when we cross-classified BCAA levels 10 years apart. However, we observed a threefold increase in breast cancer risk for NHS participants with low isoleucine levels in the first sample but high isoleucine levels in the second sample (low/high) compared with participants who had low isoleucine levels in both timepoints (low/low; Table 6).

Interactions with BMI were not statistically significant (Supplementary Table 1, available online). There were no statistically significant associations between BCAA levels and breast cancer risk by estrogen receptor (ER) status (Supplementary Table 2, available online).

In breast tumor gene expression analyses, similar pathway activity was observed for each of the individual BCAAs. Circulating BCAA levels were associated with upregulation of mTOR signaling, interferon response, MYC targets, E2F targets, G2M targets, and DNA repair among NHSII women $(73.2 \%$ 
Table 2. Characteristics of the WHS ${ }^{a}$

\begin{tabular}{|c|c|c|}
\hline Participant characteristics & WHS premenopausal at blood collection & WHS postmenopausal at blood collection \\
\hline Total, No. (\%) & $12413(46.0)$ & $14587(54.0)$ \\
\hline Mean age at blood collection (SD), y & $50.2(3.5)$ & $58.5(7.1)$ \\
\hline Mean age at menarche (SD), y & $12.4(1.4)$ & $12.5(1.5)$ \\
\hline \multicolumn{3}{|l|}{ Parity and age at first birth, \%: } \\
\hline Nulliparous & 22.4 & 22.8 \\
\hline $1-2$ children $<30 y$ & 27.2 & 18.0 \\
\hline $3+$ children $<30 y$ & 28.7 & 33.6 \\
\hline 1- 2 children $\geq 30 y$ & 5.8 & 3.8 \\
\hline $3+$ children $\geq 30 y$ & 1.6 & 2.2 \\
\hline Unknown & 14.4 & 19.7 \\
\hline Family history of breast cancer, $\%$ & 5.7 & 6.5 \\
\hline Personal history of benign breast disease, $\%$ & 32.5 & 27.6 \\
\hline Mean BMI at blood draw (SD), $\mathrm{kg} / \mathrm{m}^{2}$ & $26.0(5.2)$ & $25.8(4.8)$ \\
\hline Mean physical activity (SD), MET-h/wk & $14.8(18.6)$ & $14.8(18.3)$ \\
\hline \multicolumn{3}{|l|}{ Alcohol consumption, frequency of intake, \% } \\
\hline Rarely/never & 42.6 & 45.0 \\
\hline $1-3 / \mathrm{mo}$ & 13.7 & 13.0 \\
\hline $1-6 /$ wk & 34.3 & 30.8 \\
\hline $1+/ d$ & 9.3 & 11.3 \\
\hline Past/current exogenous hormone use, \% & 29.7 & 69.9 \\
\hline Fasting ( $>8 \mathrm{~h}$ ) at blood collection, $\%$ & 70.1 & 73.8 \\
\hline Caucasian, \% & 94.4 & 94.6 \\
\hline
\end{tabular}

'BMI = body mass index; MET = metabolic equivalent task; WHS = Women's Health Study.

premenopausal at blood collection) but with upregulation of estrogen response among NHS participants (all postmenopausal women; Supplementary Table 3, available online).

\section{Discussion}

In this prospective analysis, elevated circulating BCAA levels were associated with lower breast cancer risk among premenopausal women at blood collection but higher breast cancer risk among postmenopausal women at blood collection with proximate ( $<10$ years before diagnosis) assessments, independent of adiposity measures. Associations were similar across individual and total BCAAs. Both inverse and positive associations were slightly stronger with statistically significant linear trends among fasting women (statistically significant predictor of circulating BCAA levels), which may better reflect underlying metabolic dysregulation compared with samples collected shortly after meals, when BCAA levels may be more likely to reflect recent dietary intake than long-term metabolic state (18). Statistically significant associations generally were not observed when assessing distant measures of BCAAs among postmenopausal women. We did not observe interactions with BMI or heterogeneity by ER status. Associations did not validate in WHS.

BCAAs are essential nutrients acquired from food or biosynthesized by the microbiome (19). Several studies found a weak positive correlation between dietary BCAA intake and circulating BCAAs ( $r=0.11-0.14)$ (20-23). Similarly, we observed that dietary intake was a statistically significant but fairly weak predictor of circulating levels. Diets high in animal protein, especially red meat, are associated with increased BCAA levels compared with those with predominately plant sources of protein (23-26), and higher intake of red meat is associated with increased risk of pre- and postmenopausal breast cancer $(27,28)$. However, BCAAs were not identified as markers of dietary patterns (29) or dietary intake, suggesting the role of BCAAs in breast cancer etiology may reflect mechanisms beyond their dietary intake.
The role of obesity in postmenopausal breast cancer is well established $(30,31)$, and diabetes and insulin resistance have been associated with breast cancer risk (32). Elevated levels of circulating BCAAs are associated with obesity and insulin resistance in cross-sectional studies $(5,33,34)$ and with incident Type II diabetes $(23,35)$. Adiposity and insulin resistance have a causal effect on serum BCAA levels (36-38), and circulating BCAAs play a causal role in the development of Type II diabetes (20). Together, these findings emphasize that elevated BCAA levels are indicative of dysregulated metabolism. Further, dietary BCAAs in experimental and human studies cause impaired insulin activity through upregulation of the MTOR pathway $(39,40)$, which has been implicated in breast carcinogenesis (41).

Our observed opposite associations between plasma BCAAs and breast cancer risk by menopausal status parallel the associations between BMI and breast cancer, though associations with BCAAs persisted even with adjustment for different adiposity measures and was independent of plasma estradiol levels. We also observed differential associations by menopausal status between circulating BCAAs and breast tumor gene expression, with mTOR and interferon signaling and DNA repair among premenopausal women at blood collection, but estrogen response among postmenopausal women. These findings suggest that BCAAs play a role in breast carcinogenesis beyond their role in obesity.

Few epidemiologic studies have investigated the association of circulating BCAA levels with breast cancer risk, and only one assessed this relationship by menopausal status. No statistically significant association was observed between BCAAs and breast cancer risk (7) in a case-cohort analysis in the European Prospective Investigation into Cancer and Nutrition (EPIC) Heidelberg cohort (114 pre- and 248 postmenopausal cases) or in a larger study (6) in EPIC (434 pre-, 318 peri-, and 872 postmenopausal cases). Higher levels of valine were associated with increased breast cancer risk among pre- and postmenopausal women within the "SUpplementation en VItamines et 
Table 3. Effect estimates for predictors of probit transformed circulating BCAA levels from multivariable linear regression among 9112 NHS and NHSII women

\begin{tabular}{|c|c|c|c|c|}
\hline Predictors & No. & $\begin{array}{c}\text { Isoleucine } \\
\beta(95 \% \mathrm{CI})\end{array}$ & $\begin{array}{c}\text { Leucine } \\
\beta(95 \% \text { CI })\end{array}$ & $\begin{array}{c}\text { Valine } \\
\beta(95 \% \text { CI })\end{array}$ \\
\hline \multicolumn{5}{|l|}{ Dietary intake $^{\mathrm{a}}, \mathrm{mg} / \mathrm{d}$} \\
\hline Q1 & $1999-2010$ & Ref & Ref & Ref \\
\hline Q2 & $2016-2026$ & 0.10 (0.03 to 0.16$)$ & 0.09 (0.03 to 0.16$)$ & 0.11 (0.05 to 0.17$)$ \\
\hline Q3 & 2014-2030 & 0.13 (0.06 to 0.20$)$ & 0.18 (0.11 to 0.25$)$ & 0.26 (0.20 to 0.33$)$ \\
\hline Q4 & $2011-2034$ & 0.16 (0.08 to 0.24$)$ & 0.21 (0.13 to 0.28$)$ & 0.31 (0.23 to 0.39$)$ \\
\hline Q5 & $2025-2034$ & 0.21 (0.11 to 0.31$)$ & 0.28 (0.18 to 0.37$)$ & $0.42(0.32$ to 0.51$)$ \\
\hline$P_{\text {trend }}$ & & $<.001$ & $<.001$ & $<.001$ \\
\hline \multicolumn{5}{|l|}{ Fasting status } \\
\hline Fasting $(>8 \mathrm{~h})$ & 7836 & Ref & Ref & Ref \\
\hline Nonfasting & 2771 & 0.20 (0.16 to 0.25$)$ & 0.11 (0.07 to 0.15$)$ & 0.10 (0.06 to 0.15$)$ \\
\hline \multicolumn{5}{|l|}{ Age at blood collection, $\mathrm{y}$} \\
\hline$<40$ & 574 & Ref & Ref & Ref \\
\hline $40-50$ & 3829 & $0.00(-0.09$ to 0.09$)$ & $-0.04(-0.13$ to 0.05$)$ & $0.04(-0.05$ to 0.13$)$ \\
\hline $50-60$ & 3541 & $0.00(-0.11$ to 0.11$)$ & $-0.03(-0.14$ to 0.08$)$ & 0.12 (0.01 to 0.23$)$ \\
\hline$>60$ & 2665 & $0.02(-0.10$ to 0.14$)$ & $-0.03(-0.15$ to 0.09$)$ & $0.12(<0.01$ to 0.23$)$ \\
\hline$P_{\text {trend }}$ & & .47 & .95 & .04 \\
\hline \multicolumn{5}{|l|}{ Race } \\
\hline Caucasian & 10248 & Ref & Ref & Ref \\
\hline Black & 264 & $-0.11(-0.26$ to 0.04$)$ & $-0.04(-0.19$ to 0.11$)$ & $-0.19(-0.33$ to -0.04$)$ \\
\hline Asian & 68 & $0.28(0.03$ to 0.53$)$ & 0.26 (0.01 to 0.51$)$ & 0.34 (0.09 to 0.58 ) \\
\hline Other & 29 & $0.03(-0.34$ to 0.40$)$ & $0.06(-0.31$ to 0.43$)$ & $-0.01(-0.37$ to 0.35$)$ \\
\hline \multicolumn{5}{|l|}{ Smoking status } \\
\hline Never & 5602 & Ref & Ref & Ref \\
\hline Past & 3722 & $-0.01(-0.05$ to 0.04$)$ & $0.01(-0.03$ to 0.06$)$ & $0.01(-0.04$ to 0.05$)$ \\
\hline Current & 1263 & $0.01(-0.06$ to 0.07$)$ & $0.00(-0.06$ to 0.07$)$ & $-0.02(-0.09$ to 0.04$)$ \\
\hline \multicolumn{5}{|l|}{ BMI, $\mathrm{kg} / \mathrm{m}^{2}$} \\
\hline$<25$ & 5601 & Ref & Ref & Ref \\
\hline $25-30$ & 3154 & 0.34 (0.3 to 0.38$)$ & 0.34 (0.3 to 0.39$)$ & $0.40(0.36$ to 0.45$)$ \\
\hline$\geq 30$ & 1822 & 0.70 (0.65 to 0.76$)$ & 0.68 (0.62 to 0.74$)$ & 0.82 (0.77 to 0.88 ) \\
\hline$P_{\text {trend }}$ & & $<.001$ & $<.001$ & $<.001$ \\
\hline \multicolumn{5}{|l|}{ Physical activity, MET-h/wk } \\
\hline$<9$ & 4734 & Ref & & \\
\hline $9-27$ & 3718 & $-0.05(-0.09$ to 0.00$)$ & -0.05 ( -0.09 to 0.00$)$ & $-0.04(-0.09$ to 0.00$)$ \\
\hline$\geq 27$ & 1946 & $-0.01(-0.06$ to 0.05$)$ & $0.01(-0.05$ to 0.07$)$ & $0.01(-0.04$ to 0.06$)$ \\
\hline$P_{\text {trend }}$ & & .62 & .88 & .88 \\
\hline \multicolumn{5}{|l|}{ Alcohol consumption, g/d } \\
\hline 0 & 3531 & Ref & Ref & Ref \\
\hline $0.88-10$ & 4309 & $-0.08(-0.13$ to -0.04$)$ & $-0.07(-0.11$ to -0.02$)$ & $-0.04(-0.09$ to 0.00$)$ \\
\hline $10-20$ & 1099 & $-0.12(-0.19$ to -0.06$)$ & $-0.07(-0.14$ to -0.01$)$ & $-0.07(-0.14$ to -0.01$)$ \\
\hline$\geq 20$ & 632 & $-0.26(-0.34$ to -0.17$)$ & $-0.16(-0.25$ to -0.08$)$ & $-0.18(-0.26$ to -0.10$)$ \\
\hline$P_{\text {trend }}$ & & $<.001$ & $<.001$ & $<.001$ \\
\hline \multicolumn{5}{|c|}{ Alternative Healthy Eating Index ${ }^{b}$} \\
\hline$<37.9$ & 1909 & Ref & Ref & Ref \\
\hline$[37.9-43.5)$ & 1906 & $-0.04(-0.10$ to 0.02$)$ & $-0.01(-0.07$ to 0.05$)$ & $-0.01(-0.05$ to 0.07$)$ \\
\hline$[43.5,49)$ & 1910 & $-0.07(-0.13$ to -0.01$)$ & $-0.04(-0.10$ to 0.03$)$ & $-0.04(-0.10$ to 0.02$)$ \\
\hline$[49,55.6)$ & 1908 & $-0.10(-0.16$ to -0.03$)$ & $-0.06(-0.13$ to 0.00$)$ & $-0.04(-0.10$ to 0.02$)$ \\
\hline$\geq 55.6$ & 1909 & $-0.08(-0.15$ to -0.02$)$ & $-0.04(-0.10$ to 0.03$)$ & $-0.02(-0.08$ to 0.04$)$ \\
\hline$P_{\text {trend }}$ & & .001 & .07 & .20 \\
\hline \multicolumn{5}{|c|}{ Menopausal status and PMH use } \\
\hline Premenopausal & 4337 & Ref & Ref & Ref \\
\hline Postmenopausal PMH & 2447 & $0.05(-0.02$ to 0.11$)$ & $0.06(-0.01$ to 0.12$)$ & 0.12 (0.06 to 0.18$)$ \\
\hline Postmenopausal no $\mathrm{PMH}$ & 3189 & 0.10 (0.04 to 0.17$)$ & 0.15 (0.08 to 0.22$)$ & 0.17 (0.11 to 0.24$)$ \\
\hline Unknown & 649 & $0.08(-0.01$ to 0.17$)$ & $0.06(-0.04$ to 0.15$)$ & $0.10(0.00$ to 0.19$)$ \\
\hline
\end{tabular}

${ }^{a}$ Number and cutpoints vary by BCAA: isoleucine dietary intake quintile cutpoints $[\mathrm{mg} / \mathrm{d}]:<2.86 ;[2.86,3.47) ;[3.47,4.06) ;[4.06,4.82) ; \geq 4.82$. Leucine dietary intake quintile cutpoints [mg/d]: $<5.33 ;[5.33,6.49) ;[6.49,7.58) ;[7.58,9.05) ; \geq 9.05$. Valine dietary intake quintile cutpoints [mg/d]: $<3.22 ;[3.22,3.93) ;[3.93,4.59) ;[4.59,5.47) ; \geq 5.47$. BCAA $=$ branched-chain amino acid; $\mathrm{CI}=$ confidence interval; $\mathrm{MET}=$ metabolic equivalent task; NHS = Nurses' Health Study; NHSII = Nurses' Health Study II; PMH = postmenopausal hormone therapy; $\mathrm{Q}=$ quintile.

${ }^{\mathrm{b}}$ Calculated without alcohol intake. 
Table 4. OR of breast cancer according to quartiles of plasma BCAA among premenopausal and postmenopausal women

\begin{tabular}{|c|c|c|c|c|c|}
\hline BCAA & Q1 & Q2 & Q3 & Q4 & $P_{\text {trend }}$ \\
\hline $\begin{array}{l}\text { Premenopausal }{ }^{\mathrm{a}} \text { women at blood } \\
\text { collection in NHSII }(\mathrm{N}=1057 \mathrm{cc} \\
\text { Isoleucine }\end{array}$ & & & & & \\
\hline \multicolumn{6}{|l|}{ All samples } \\
\hline No. of cases/controls & $300 / 265$ & $282 / 264$ & $239 / 264$ & $236 / 264$ & \\
\hline Simple ${ }^{\mathrm{b}}$ OR $(95 \% \mathrm{CI})$ & Ref & $0.93(0.73$ to 1.18$)$ & $0.79(0.61$ to 1.01$)$ & $0.76(0.59$ to 0.99$)$ & .02 \\
\hline Multivariable ${ }^{c}$ OR $(95 \% \mathrm{CI})$ & Ref & 0.99 (0.77 to 1.27$)$ & 0.87 (0.67 to 1.13$)$ & 0.86 (0.65 to 1.13$)$ & .20 \\
\hline \multicolumn{6}{|l|}{ Fasting samples } \\
\hline No. of cases/controls & $216 / 179$ & $201 / 179$ & $149 / 178$ & $149 / 179$ & \\
\hline Multivariable ${ }^{\mathrm{C}} \mathrm{OR}(95 \% \mathrm{CI})$ & Ref & 0.97 (0.72 to 1.30$)$ & 0.77 (0.56 to 1.05$)$ & 0.74 (0.53 to 1.05$)$ & .05 \\
\hline \multicolumn{6}{|l|}{ Leucine } \\
\hline \multicolumn{6}{|l|}{ All samples } \\
\hline No. of cases/controls & $296 / 265$ & $268 / 264$ & $278 / 264$ & $215 / 264$ & \\
\hline Simple $^{\mathrm{b}}$ OR $(95 \% \mathrm{CI})$ & Ref & 0.90 (0.70 to 1.14$)$ & 0.93 (0.72 to 1.19$)$ & 0.71 (0.55 to 0.92$)$ & .02 \\
\hline Multivariable ${ }^{c}$ OR $(95 \% \mathrm{CI})$ & Ref & $0.92(0.72$ to 1.18$)$ & $1.00(0.77$ to 1.30$)$ & 0.77 (0.58 to 1.01$)$ & .11 \\
\hline \multicolumn{6}{|l|}{ Fasting samples } \\
\hline No. of cases/controls & 209/179 & $184 / 179$ & $190 / 178$ & $132 / 179$ & \\
\hline Multivariable ${ }^{\mathrm{C}}$ OR $(95 \% \mathrm{CI})$ & Ref & 0.88 (0.66 to 1.18$)$ & 0.94 (0.68 to 1.29$)$ & 0.66 (0.47 to 0.94$)$ & .04 \\
\hline \multicolumn{6}{|l|}{ Valine } \\
\hline \multicolumn{6}{|l|}{ All samples } \\
\hline No. of cases/controls & $293 / 265$ & $262 / 264$ & $283 / 264$ & $219 / 264$ & \\
\hline Simple ${ }^{\mathrm{b}}$ OR $(95 \%$ CI $)$ & Ref & 0.89 (0.69 to 1.13$)$ & $0.95(0.75$ to 1.20$)$ & 0.74 (0.58 to 0.95$)$ & .04 \\
\hline Multivariable ${ }^{c}$ OR $(95 \% \mathrm{CI})$ & Ref & 0.91 (0.71 to 1.18$)$ & 1.02 (0.80 to 1.31$)$ & 0.82 (0.62 to 1.08$)$ & .28 \\
\hline \multicolumn{6}{|l|}{ Fasting samples } \\
\hline No. of cases/controls & $217 / 179$ & $181 / 179$ & $170 / 178$ & $147 / 179$ & \\
\hline Multivariable ${ }^{c}$ OR $(95 \% \mathrm{CI})$ & Ref & 0.86 (0.63 to 1.16$)$ & 0.81 (0.60 to 1.10$)$ & 0.74 (0.53 to 1.04$)$ & .08 \\
\hline \multicolumn{6}{|l|}{ Total BCAA } \\
\hline \multicolumn{6}{|l|}{ All samples } \\
\hline No. of cases/controls & $278 / 265$ & $293 / 264$ & $257 / 264$ & $229 / 264$ & \\
\hline Simple ${ }^{\mathrm{b}}$ OR $(95 \% \mathrm{CI})$ & Ref & 1.05 (0.83 to 1.34$)$ & 0.92 (0.72 to 1.18$)$ & 0.81 (0.63 to 1.05$)$ & .07 \\
\hline Multivariable ${ }^{c}$ OR $(95 \% \mathrm{CI})$ & Ref & 1.10 (0.86 to 1.41$)$ & 0.99 (0.77 to 1.28$)$ & 0.91 (0.69 to 1.19$)$ & .41 \\
\hline \multicolumn{6}{|l|}{ Fasting samples } \\
\hline No. of cases/controls & $206 / 179$ & 198/179 & $166 / 178$ & $145 / 179$ & \\
\hline Multivariable ${ }^{c}$ OR $(95 \%$ CI) & Ref & 1.02 (0.76 to 1.38$)$ & 0.85 (0.62 to 1.16$)$ & $0.79(0.56$ to 1.11$)$ & .12 \\
\hline \multirow{2}{*}{\multicolumn{6}{|c|}{$\begin{array}{l}\text { Postmenopausal }{ }^{\mathrm{d}} \text { women in NHS, distant sample } \\
\text { collection (10-20 y before diagnosis, } \mathrm{N}=940 \text { cases/controls) }\end{array}$}} \\
\hline & & & & & \\
\hline \multicolumn{6}{|c|}{ Isoleucine } \\
\hline \multicolumn{6}{|l|}{ All samples } \\
\hline No. of cases/controls & $226 / 235$ & $220 / 235$ & $205 / 235$ & $289 / 235$ & \\
\hline Simple ${ }^{\mathrm{b}}$ OR $(95 \% \mathrm{CI})$ & Ref & $0.98(0.75$ to 1.26$)$ & $0.92(0.70$ to 1.19$)$ & 1.29 (1.00 to 1.67$)$ & .05 \\
\hline Multivariable ${ }^{\mathrm{C}}$ OR $(95 \% \mathrm{CI})$ & Ref & $0.95(0.73$ to 1.24$)$ & 0.83 (0.63 to 1.09$)$ & 1.15 (0.87 to 1.52$)$ & .35 \\
\hline Fasting samples & & & & & \\
\hline No. of cases/controls & $157 / 156$ & $132 / 156$ & $150 / 155$ & $184 / 156$ & \\
\hline Multivariable ${ }^{\mathrm{C}} \mathrm{OR}(95 \% \mathrm{CI})$ & Ref & 0.83 (0.60 to 1.15$)$ & 0.84 (0.60 to 1.18$)$ & $0.98(0.69$ to 1.39$)$ & .97 \\
\hline Leucine & & & & & \\
\hline All samples & & & & & \\
\hline No. of cases/controls & $220 / 235$ & $217 / 235$ & $215 / 235$ & $288 / 235$ & \\
\hline Simple ${ }^{\mathrm{b}}$ OR $(95 \% \mathrm{CI})$ & Ref & 0.98 (0.75 to 1.29$)$ & 0.98 (0.76 to 1.28$)$ & 1.32 (1.02 to 1.72$)$ & .03 \\
\hline Multivariable ${ }^{\mathrm{C}}$ OR $(95 \% \mathrm{CI})$ & Ref & 0.95 (0.72 to 1.25$)$ & 0.90 (0.68 to 1.18$)$ & 1.19 (0.90 to 1.58$)$ & .24 \\
\hline Fasting samples & & & & & \\
\hline No. of cases/controls & $147 / 156$ & $145 / 156$ & $141 / 155$ & $190 / 156$ & \\
\hline Multivariable ${ }^{\mathrm{C}}$ OR $(95 \% \mathrm{CI})$ & Ref & 0.95 (0.68 to 1.33$)$ & 0.83 (0.59 to 1.17 ) & $1.08(0.75$ to 1.56$)$ & .86 \\
\hline Valine & & & & & \\
\hline All samples & & & & & \\
\hline No. of cases/controls & $215 / 235$ & $236 / 235$ & $233 / 235$ & $256 / 235$ & \\
\hline Simple ${ }^{b}$ OR $(95 \%$ CI $)$ & Ref & 1.10 (0.85 to 1.42$)$ & 1.08 (0.84 to 1.40$)$ & $1.20(0.92$ to 1.55$)$ & .20 \\
\hline Multivariable ${ }^{\mathrm{c}}$ OR $(95 \% \mathrm{CI})$ & Ref & 1.03 (0.79 to 1.34$)$ & 0.99 (0.76 to 1.29$)$ & 1.05 (0.80 to 1.40$)$ & .77 \\
\hline Fasting samples & & & & & \\
\hline No. of cases/controls & $146 / 156$ & $161 / 156$ & $137 / 155$ & $179 / 156$ & \\
\hline Multivariable ${ }^{\mathrm{C}}$ OR $(95 \% \mathrm{CI})$ & Ref & 1.01 (0.72 to 1.41$)$ & 0.82 (0.58 to 1.15$)$ & 1.03 (0.72 to 1.47$)$ & .90 \\
\hline
\end{tabular}


Table 4. (continued)

\begin{tabular}{|c|c|c|c|c|c|}
\hline BCAA & Q1 & Q2 & Q3 & Q4 & $P_{\text {trend }}$ \\
\hline \multicolumn{6}{|l|}{ Total BCAA } \\
\hline \multicolumn{6}{|l|}{ All samples } \\
\hline No. of cases/controls & $217 / 235$ & $225 / 235$ & $217 / 235$ & $281 / 235$ & \\
\hline Simple ${ }^{\mathrm{b}}$ OR $(95 \% \mathrm{CI})$ & Ref & 1.04 (0.80 to 1.35$)$ & $1.00(0.78$ to 1.29$)$ & $1.32(1.02$ to 1.70$)$ & .05 \\
\hline Multivariable ${ }^{c}$ OR $(95 \%$ CI $)$ & Ref & 0.99 (0.75 to 1.30$)$ & 0.91 (0.69 to 1.19$)$ & 1.17 (0.88 to 1.55$)$ & .33 \\
\hline \multicolumn{6}{|l|}{ Fasting samples } \\
\hline No. of cases/controls & $142 / 156$ & $148 / 156$ & $150 / 155$ & $183 / 156$ & \\
\hline Multivariable ${ }^{c}$ OR $(95 \%$ CI $)$ & Ref & $1.00(0.72$ to 1.40$)$ & 0.91 (0.65 to 1.28$)$ & 1.06 (0.74 to 1.52$)$ & .88 \\
\hline \multicolumn{6}{|c|}{$\begin{array}{l}\text { Postmenopausal }{ }^{\mathrm{d}} \text { women in NHS, proximate sample } \\
\text { collection ( }<10 \text { y before diagnosis, } N=592 \text { cases/controls) }\end{array}$} \\
\hline \multicolumn{6}{|l|}{ Isoleucine } \\
\hline \multicolumn{6}{|l|}{ All samples } \\
\hline No. of cases/controls & $112 / 148$ & $146 / 148$ & $154 / 148$ & $180 / 148$ & \\
\hline Simpleb OR (95\% CI) & Ref & 1.30 (0.94 to 1.81$)$ & 1.39 (1.00 to 1.95$)$ & 1.63 (1.17 to 2.29$)$ & .01 \\
\hline Multivariable ${ }^{c}$ OR $(95 \%$ CI $)$ & Ref & 1.29 (0.91 to 1.83$)$ & 1.45 (1.01 to 2.09$)$ & 1.63 (1.12 to 2.39$)$ & .01 \\
\hline \multicolumn{6}{|l|}{ Fasting samples } \\
\hline No. of cases/controls & $91 / 129$ & $130 / 128$ & $136 / 128$ & $156 / 128$ & \\
\hline Multivariable ${ }^{c}$ OR $(95 \%$ CI $)$ & Ref & 1.49 (1.02 to 2.17$)$ & 1.59 (1.06 to 2.37$)$ & 1.73 (1.15 to 2.61$)$ & .01 \\
\hline \multicolumn{6}{|l|}{ Leucine } \\
\hline \multicolumn{6}{|l|}{ All samples } \\
\hline No. of cases/controls & $123 / 148$ & $144 / 148$ & $164 / 148$ & $161 / 148$ & \\
\hline Simple ${ }^{\mathrm{b}}$ OR $(95 \% \mathrm{CI})$ & Ref & 1.17 (0.83 to 1.63$)$ & 1.33 (0.96 to 1.84$)$ & 1.32 (0.94 to 1.84$)$ & .08 \\
\hline Multivariable ${ }^{c}$ OR $(95 \%$ CI $)$ & Ref & 1.20 (0.84 to 1.71$)$ & 1.43 (1.01 to 2.03$)$ & $1.26(0.87$ to 1.83$)$ & .17 \\
\hline \multicolumn{6}{|l|}{ Fasting samples } \\
\hline No. of cases/controls & $103 / 129$ & $123 / 128$ & $147 / 128$ & $140 / 128$ & \\
\hline Multivariable ${ }^{c}$ OR (95\% CI) & Ref & 1.29 (0.88 to 1.90$)$ & 1.58 (1.08 to 2.31$)$ & 1.31 (0.87 to 1.98$)$ & .12 \\
\hline \multicolumn{6}{|l|}{ Valine } \\
\hline \multicolumn{6}{|l|}{ All samples } \\
\hline No. of cases/controls & $119 / 148$ & $146 / 148$ & $158 / 148$ & $169 / 148$ & \\
\hline Simple ${ }^{\mathrm{b}}$ OR $(95 \%$ CI $)$ & Ref & 1.21 (0.87 to 1.68$)$ & 1.31 (0.95 to 1.80$)$ & $1.42(1.02$ to 1.98$)$ & .03 \\
\hline Multivariable ${ }^{c}$ OR $(95 \%$ CI $)$ & Ref & 1.23 (0.87 to 1.73$)$ & 1.33 (0.94 to 1.88$)$ & 1.34 (0.93 to 1.94$)$ & .12 \\
\hline \multicolumn{6}{|l|}{ Fasting samples } \\
\hline No. of cases/controls & $99 / 129$ & $134 / 128$ & $111 / 128$ & $169 / 128$ & \\
\hline Multivariable ${ }^{c}$ OR $(95 \%$ CI) & Ref & 1.45 (1.00 to 2.10$)$ & 1.13 (0.76 to 1.67$)$ & 1.64 (1.11 to 2.43$)$ & .04 \\
\hline \multicolumn{6}{|l|}{ Total BCAA } \\
\hline \multicolumn{6}{|l|}{ All samples } \\
\hline No. of cases/controls & $119 / 148$ & $149 / 148$ & $148 / 148$ & $176 / 148$ & \\
\hline Simple ${ }^{\mathrm{b}}$ OR $(95 \% \mathrm{CI})$ & Ref & $1.25(0.90$ to 1.74$)$ & $1.25(0.90$ to 1.74$)$ & 1.49 (1.07 to 2.08$)$ & .02 \\
\hline Multivariable ${ }^{\mathrm{c}}$ OR $(95 \% \mathrm{CI})$ & Ref & 1.30 (0.92 to 1.85$)$ & 1.35 (0.94 to 1.93$)$ & 1.45 (1.00 to 2.09$)$ & .06 \\
\hline \multicolumn{6}{|l|}{ Fasting samples } \\
\hline No. of cases/controls & $101 / 129$ & $129 / 128$ & $123 / 128$ & $160 / 128$ & \\
\hline Multivariable $^{c}$ OR $(95 \% \mathrm{CI})$ & Ref & 1.41 (0.96 to 2.08$)$ & 1.35 (0.92 to 1.98$)$ & 1.56 (1.04 to 2.34$)$ & .06 \\
\hline
\end{tabular}

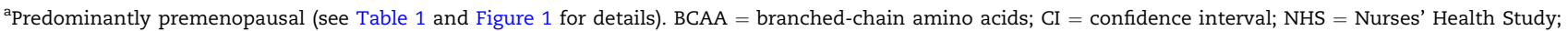
NHSII = Nurses' Health Study II; OR = odds ratios; Q = quartile.

${ }^{b}$ Simple model: no adjustment factors were included.

${ }^{\mathrm{C}}$ Multivariable model: BMI at age 18 years, weight change from age 18 years to time of blood draw, age at menarche, parity and age at first birth, family history of breast cancer, history of benign breast disease, physical activity, alcohol consumption, exogenous hormone use, and breastfeeding history.

${ }^{\mathrm{d}}$ Predominantly postmenopausal women (see Table 1 and Figure 1 for details).

MinérauxAntioXydants" (SU.VI.MAX) study (129 pre- and 82 postmenopausal cases) (8). Given the mix of menopausal status, it is difficult to compare these results with our findings. Consistent with our results, in an examination of BMI-correlated metabolites in the Prostate, Lung, Colorectal and Ovarian Cancer Screening Trial (PLCO), which included valine and allo-isoleucine ( $\mathrm{N}=621$ postmenopausal cases), higher levels of allo-isoleucine, a byproduct of isoleucine transamination (42), were associated with increased postmenopausal breast cancer risk (9). Notably, 2 other metabolites involved in alternative isoleucine and leucine degradation, 2-methylbutyrylcarnitine and 3-methylglutarylcarnitine, were positively associated with risk (9). Sensitivity analyses adjusting for insulin resistance-related metabolites resulted in slight attenuation of the associations. Similarly, we observed no changes when adjusting for C-peptide, a measure of insulin production, suggesting that the role of BCAAs in postmenopausal breast cancer etiology may be independent of insulin resistance. In summary, results from PLCO, NHS, and NHSII suggest that isoleucine and leucine may play a role in postmenopausal breast cancer, although findings from WHS were not consistent. However, to what extent individual BCAAs contribute to breast cancer and how this relationship is modulated by menopausal status is not clear. Additional prospective studies are needed to confirm these relationships. 
Table 5. ORs of breast cancer according to quartiles of plasma BCAA among premenopausal and postmenopausal women in WHS

\begin{tabular}{|c|c|c|c|c|c|}
\hline BCAA & Q1 & Q2 & Q3 & Q4 & $P_{\text {trend }}$ \\
\hline \multicolumn{6}{|l|}{$\begin{array}{l}\text { Premenopausal women at blood } \\
\text { collection in WHS ( } \mathrm{N}=763 \text { cases) } \\
\text { Isoleucine }\end{array}$} \\
\hline No. of cases/noncases & $191 / 2873$ & $188 / 2906$ & $190 / 2891$ & $194 / 2980$ & \\
\hline Multivariable $^{\mathrm{a}}$ OR $(95 \% \mathrm{CI})$ & Ref & 0.98 (0.80 to 1.20$)$ & 0.99 (0.81 to 1.21$)$ & 0.99 (0.80 to 1.20$)$ & .93 \\
\hline \multicolumn{6}{|l|}{ Leucine } \\
\hline No. of cases/noncases & $183 / 3000$ & $187 / 2903$ & $213 / 2798$ & $180 / 2949$ & \\
\hline Multivariable ${ }^{\mathrm{a}}$ OR $(95 \% \mathrm{CI})$ & Ref & 1.06 (0.87 to 1.31$)$ & 1.22 (1.00 to 1.49$)$ & 1.00 (0.81 to 1.24$)$ & .62 \\
\hline \multicolumn{6}{|l|}{ Valine } \\
\hline No. of cases/noncases & $206 / 3081$ & $187 / 2849$ & $179 / 2836$ & $191 / 2884$ & \\
\hline Multivariable ${ }^{\mathrm{a}}$ OR $(95 \% \mathrm{CI})$ & Ref & 0.98 (0.80 to 1.20$)$ & 0.95 (0.77 to 1.16$)$ & 0.97 (0.79 to 1.20$)$ & .76 \\
\hline \multicolumn{6}{|l|}{ Total BCAA } \\
\hline No. of cases/noncases & $196 / 3058$ & $181 / 2850$ & $193 / 2780$ & $193 / 2962$ & \\
\hline Multivariable ${ }^{\mathrm{a}}$ OR $(95 \% \mathrm{CI})$ & Ref & 0.98 (0.80 to 1.21$)$ & 1.07 (0.88 to 1.32$)$ & 1.01 (0.82 to 1.25$)$ & .76 \\
\hline \multicolumn{6}{|c|}{$\begin{array}{l}\text { Postmenopausal women in WHS, distant sample } \\
\text { collection (10-20 y before diagnosis, } \mathrm{N}=515 \text { cases) } \\
\text { Isoleucine }\end{array}$} \\
\hline No. of cases/noncases & $125 / 3561$ & $118 / 3538$ & $144 / 3525$ & $128 / 3448$ & \\
\hline Multivariable $^{\mathrm{a}}$ OR $(95 \% \mathrm{CI})$ & Ref & 0.94 (0.73 to 1.21$)$ & 1.16 (0.91 to 1.47$)$ & 1.11 (0.86 to 1.43$)$ & .25 \\
\hline \multicolumn{6}{|l|}{ Leucine } \\
\hline No. of cases/noncases & $121 / 3446$ & $105 / 3555$ & $146 / 3593$ & $143 / 3478$ & \\
\hline Multivariable $^{\mathrm{a}}$ OR $(95 \% \mathrm{CI})$ & Ref & 0.85 (0.65 to 1.10$)$ & 1.15 (0.90 to 1.47$)$ & 1.23 (0.96 to 1.58$)$ & .04 \\
\hline \multicolumn{6}{|l|}{ Valine } \\
\hline No. of cases/noncases & $127 / 3336$ & $127 / 3587$ & $129 / 3606$ & $132 / 3543$ & \\
\hline Multivariable $^{\mathrm{a}}$ OR $(95 \% \mathrm{CI})$ & Ref & 0.94 (0.73 to 1.21$)$ & 0.95 (0.74 to 1.22$)$ & 0.99 (0.76 to 1.29$)$ & .95 \\
\hline \multicolumn{6}{|l|}{ Total BCAA } \\
\hline No. of cases/noncases & $127 / 3369$ & $121 / 3598$ & $135 / 3642$ & $132 / 3463$ & \\
\hline Multivariable $^{\mathrm{a}}$ OR $(95 \% \mathrm{CI})$ & Ref & 0.88 (0.69 to 1.13$)$ & 0.98 (0.76 to 1.25$)$ & 1.05 (0.81 to 1.36$)$ & .60 \\
\hline \multirow{2}{*}{\multicolumn{6}{|c|}{$\begin{array}{l}\text { Postmenopausal women in WHS, proximate sample } \\
\text { collection ( }<10 \text { y before diagnosis, } \mathrm{N}=487 \text { cases }) \\
\text { Isoleucine }\end{array}$}} \\
\hline & & & & & \\
\hline No. of cases/noncases & $136 / 3550$ & $116 / 3540$ & $120 / 3549$ & $115 / 3461$ & \\
\hline Multivariable $^{\mathrm{a}}$ OR $(95 \% \mathrm{CI})$ & Ref & 0.87 (0.68 to 1.12 ) & 0.93 (0.73 to 1.19 ) & 0.97 (0.75 to 1.26$)$ & .85 \\
\hline \multicolumn{6}{|l|}{ Leucine } \\
\hline No. of cases/noncases & $126 / 3441$ & $115 / 3545$ & $123 / 3616$ & $123 / 3498$ & \\
\hline Multivariable $^{\mathrm{a}}$ OR $(95 \% \mathrm{CI})$ & Ref & 0.91 (0.70 to 1.17$)$ & 0.97 (0.76 to 1.25$)$ & 1.05 (0.81 to 1.36$)$ & .68 \\
\hline \multicolumn{6}{|l|}{ Valine } \\
\hline No. of cases/noncases & $119 / 3344$ & $133 / 3581$ & $128 / 3607$ & $107 / 3568$ & \\
\hline Multivariable $^{\mathrm{a}}$ OR $(95 \% \mathrm{CI})$ & Ref & 1.09 (0.85 to 1.39$)$ & 1.04 (0.81 to 1.34$)$ & 0.96 (0.73 to 1.26$)$ & .75 \\
\hline \multicolumn{6}{|l|}{ Total BCAA } \\
\hline No. of cases/noncases & $128 / 3368$ & $119 / 3600$ & $126 / 3651$ & $114 / 3481$ & \\
\hline Multivariable $^{\mathrm{a}}$ OR $(95 \% \mathrm{CI})$ & Ref & 0.89 (0.69 to 1.15$)$ & 0.97 (0.75 to 1.24$)$ & 0.98 (0.75 to 1.27$)$ & .98 \\
\hline
\end{tabular}

${ }^{a}$ Multivariable model is adjusted for age, randomized treatment assignment, BMI, age at menarche, parity and age at first birth, family history of breast cancer, history of benign breast disease, physical activity, alcohol consumption, HRT, menopausal status, fasting status and race. BCAA = branched-chain amino acids; BMI = body mass index; $\mathrm{CI}$ = confidence interval; $\mathrm{HRT}$ = hormone replacement therapy; $\mathrm{OR}$ = odds ratios; $\mathrm{Q}$ = quartile; WHS = Women's Health Study.

Table 6. ORs of breast cancer according to 10-year change ${ }^{a}$ in plasma BCAA in postmenopausal women in NHS

\begin{tabular}{|c|c|c|c|c|}
\hline BCAA & Low/low & Low/high & High/low & High/high \\
\hline \multicolumn{5}{|l|}{ Isoleucine } \\
\hline No. of cases/controls & $118 / 96$ & $55 / 69$ & $55 / 50$ & $118 / 131$ \\
\hline Multivariable ${ }^{\mathrm{b}}$ OR $(95 \% \mathrm{CI})$ & 1.00 (ref) & 3.00 (1.45 to 6.20$)$ & 0.87 (0.41 to 1.83$)$ & 1.45 (0.77 to 2.71$)$ \\
\hline \multicolumn{5}{|l|}{ Leucine } \\
\hline No. of cases/controls & $116 / 104$ & $57 / 62$ & $57 / 50$ & $116 / 130$ \\
\hline Multivariable ${ }^{\mathrm{b}}$ OR $(95 \% \mathrm{CI})$ & 1.00 (ref) & $1.49(0.72$ to 3.08$)$ & $0.70(0.32$ to 1.50$)$ & 1.22 (0.64 to 2.33 ) \\
\hline \multicolumn{5}{|l|}{ Valine } \\
\hline No. of cases/controls & $114 / 104$ & $59 / 60$ & $59 / 65$ & $114 / 117$ \\
\hline Multivariable ${ }^{\mathrm{b}}$ OR $(95 \% \mathrm{CI})$ & 1.00 (ref) & 1.15 (0.58 to 2.28$)$ & 1.54 (0.76 to 3.11$)$ & 0.90 (0.48 to 1.69$)$ \\
\hline \multicolumn{5}{|l|}{ Total BCAA } \\
\hline No. of cases/controls & $120 / 107$ & $53 / 57$ & $53 / 55$ & $120 / 127$ \\
\hline Multivariable ${ }^{\mathrm{b}}$ OR $(95 \% \mathrm{CI})$ & 1.00 (ref) & 1.42 (0.69 to 2.93$)$ & 1.13 (0.55 to 2.33$)$ & 0.99 (0.53 to 1.85$)$ \\
\hline
\end{tabular}

${ }^{a}$ Cross-classified by median in distant or proximate sample collections. BCAA = branched-chain amino acids; CI = confidence interval; NHS = Nurses' Health Study; OR = odds ratio.

${ }^{b}$ Multivariable model: body mass index at age 18 years, weight change from age 18 years to time of blood draw, age at menarche, parity and age at first birth, family history of breast cancer, history of benign breast disease, physical activity, alcohol consumption, exogenous hormone use, and breastfeeding history. 
Our study has several strengths and limitations. We measured prediagnostic plasma BCAAs among a large number of pre- and postmenopausal women. We had detailed information on breast cancer risk factors, including measures of adiposity. We had limited statistical power in analyses of ERtumors. Although we had some participants with 2 blood samples, our main findings are based on 1-point-in-time blood samples. However, BCAAs showed good within-person stability over $1-2$ years (ICC $\geq 0.55$ ) (43) as well as good withinperson stability over 10 years (ICC $>0.4$ ). Metabolomics platforms differed between NHS and NHSII and WHS; nuclear magnetic resonance (NMR) approaches may be more limited in measuring BCAA levels (44). However, others showed good correlations and consistent associations with diabetes between the platforms (45).

In summary, elevated circulating BCAA levels were associated with higher risk of postmenopausal breast cancer in NHS when assessed within 10 years of diagnosis, independent of established risk factors, including adiposity, though this finding was not replicated among predominantly postmenopausal WHS women. Whether circulating BCAAs levels are inversely associated with breast cancer risk among premenopausal women warrants further investigation.

\section{Funding}

The NHS and NHSII are funded by the National Cancer Institute (R01 CA050385, UM1 CA186107, P01 CA087969, R01 CA49449, U01 CA176726, R01 CA67262). The WHS (CA-047988, HL-043851, HL-080467, HL-099355, and UM1 CA182913) and Dr. Mora (R01HL134811, K24 HL136852, DK112940) are supported by the National Institutes of Health.

\section{Notes}

Role of the funder: Funding agencies played no role in the study design, sample collection, data analysis, results interpretation, manuscript writing and submission.

Disclosures: The authors have nothing to disclose.

Author contributions: OAZ contributed to data curation, formal analysis, investigation, methodology, manuscript writing and manuscript review. RB and BAR contributed to investigation, methodology and manuscript review. YR and CP contributed to formal analysis and manuscript review. DKT contributed to formal analysis, investigation and manuscript review. AMB and LF contributed to resources and manuscript review. SJ, JAP and CBC contributed to data curation, resources and manuscript review. SM contributed to resources, investigation and manuscript review. FBH contributed to investigation and manuscript review. AHE contributed to conceptualization, funding acquisition, investigation, methodology, project administration, resources, supervision, manuscript writing and manuscript review.

Acknowledgements: We would like to thank the participants and staff of the Nurses' Health Studies for their valuable contributions as well as the following state cancer registries for their help: AL, AZ, AR, CA, CO, CT, DE, FL, GA, ID, IL, IN, IA, KY, LA, ME, MD, MA, MI, NE, NH, NJ, NY, NC, ND, OH, OK, OR, PA, RI, SC, TN, TX, VA, WA, WY. The authors assume full responsibility for analyses and interpretation of these data.

\section{Data Availability}

Data access must be approved by the institutional review boards of the Brigham and Women's Hospital and Harvard T.H. Chan School of Public Health. Inquiries are encouraged through http://www.nurseshealthstudy.org/researchers.

\section{References}

1. American Cancer Society. Cancer Facts and Figures 2020. Atlanta, GA: American Cancer Society; 2020.

2. Wilson LF, Page AN, Dunn NA, Pandeya N, Protani MM, Taylor RJ. Population attributable risk of modifiable risk factors associated with invasive breast cancer in women aged 45-69 years in Queensland, Australia. Maturitas. 2013; 76(4):370-376.

3. Schoemaker MJ, Nichols HB, Wright LB, et al.; Premenopausal Breast Cancer Collaborative Group. Association of body mass index and age with subsequent breast cancer risk in premenopausal women. JAMA Oncol. 2018;4(11): e181771.

4. Wolfe RR. Branched-chain amino acids and muscle protein synthesis in humans: myth or reality? J Int Soc Sports Nutr. 2017;14:30.

5. Newgard CB, An J, Bain JR, et al. A branched-chain amino acid-related metabolic signature that differentiates obese and lean humans and contributes to insulin resistance. Cell Metab. 2009;9(4):311-326.

6. His M, Viallon V, Dossus L, et al. Prospective analysis of circulating metabolites and breast cancer in EPIC. BMC Med. 2019;17(1):178.

7. Kühn T, Floegel A, Sookthai D, et al. Higher plasma levels of lysophosphatidylcholine 18: 0 are related to a lower risk of common cancers in a prospective metabolomics study. BMC Med. 2016;14:13.

8. Lécuyer L, Dalle C, Lyan B, Demidem A, Rossary A, et al. Plasma metabolomic signatures associated with long-term breast cancer risk in the SU. VI. MAX prospective cohort. Cancer Epidemiol Biomarkers Prev. 2019;28(8):1300-1307.

9. Moore SC, Playdon MC, Sampson JN, Hoover RN, Trabert B, et al. A metabolomics analysis of body mass index and postmenopausal breast cancer risk. J Natl Cancer Inst. 2018;110:588-597.

10. Tobias DK, Hazra A, Lawler PR, et al. Circulating branched-chain amino acids and long-term risk of obesity-related cancers in women. Sci Rep. 2020;10(1): $1-9$.

11. Hankinson SE, Willett WC, Michaud DS, et al. Plasma prolactin levels and subsequent risk of breast cancer in postmenopausal women. J Natl Cancer Inst. 1999;91(7):629-634.

12. Tworoger SS, Sluss P, Hankinson SE. Association between plasma prolactin concentrations and risk of breast cancer among predominately premenopausal women. Cancer Res. 2006;66(4):2476-2482.

13. Mascanfroni ID, Takenaka MC, Yeste A, et al. Metabolic control of type 1 regulatory T cell differentiation by AHR and HIF1- $\alpha$. Nat Med. 2015;21(6): 638-646.

14. O'Sullivan JF, Morningstar JE, Yang Q et al. Dimethylguanidino valeric acid is a marker of liver fat and predicts diabetes. J Clin Invest. 2017;127(12): 4394-4402.

15. Paynter NP, Balasubramanian R, Giulianini F, et al. Metabolic predictors of incident coronary heart disease in women. Circulation. 2018;137(8):841-853.

16. DerSimonian R, Laird N. Meta-analysis in clinical trials. Control Clin Trials. 1986;7(3):177-188.

17. Wu D, Smyth GK. Camera: a competitive gene set test accounting for intergene correlation. Nucleic Acids Res. 2012;40(17):e133.

18. Schmedes M, Balderas C, Aadland EK, et al. The effect of lean-seafood and non-seafood diets on fasting and postprandial serum metabolites and lipid species: results from a randomized crossover intervention study in healthy adults. Nutrients. 2018;10(5):598.

19. Ferguson JF, Wang TJ. Branched-chain amino acids and cardiovascular disease: does diet matter? Clin Chem. 2016;62(4):545-547.

20. Lotta LA, Scott RA, Sharp SJ, et al. Genetic predisposition to an impaired metabolism of the branched-chain amino acids and risk of type 2 diabetes: a Mendelian randomisation analysis. PLoS Med. 2016;13(11):e1002179.,

21. McCormack SE, Shaham O, McCarthy MA, et al. Circulating branched-chain amino acid concentrations are associated with obesity and future insulin resistance in children and adolescents. Pediatr Obes. 2013;8(1):52-61.

22. Tobias DK, Clish C, Mora S, et al. Dietary intakes and circulating concentrations of branched-chain amino acids in relation to incident type 2 diabetes risk among high-risk women with a history of gestational diabetes mellitus. Clin Chem. 2018;64(8):1203-1210.

23. Zheng Y, Li Y, Qi Q Hruby A, et al. Cumulative consumption of branchedchain amino acids and incidence of type 2 diabetes. Int J Epidemiol. 2016;45(5): 1482-1492.

24. López AM, Noriega LG, Diaz M, Torres N, Tovar AR. Plasma branched-chain and aromatic amino acid concentration after ingestion of an urban or rural diet in rural Mexican women. BMC Obes. 2015;2(8):8.

25. Merz B, Frommherz L, Rist MJ, et al. Dietary pattern and plasma BCAAvariations in healthy men and women-results from the KarMeN study. Nutrients. 2018;10(5):623. 
26. Rousseau M, Guénard F, Garneau V, et al. Associations between dietary protein sources, plasma BCAA and short-chain acylcarnitine levels in adults. Nutrients. 2019;11(1):173.

27. Guo J, Wei W, Zhan L. Red and processed meat intake and risk of breast cancer: a meta-analysis of prospective studies. Breast Cancer Res Treat. 2015; 151(1):191-198.

28. Cho E, Chen WY, Hunter DJ, et al. Red meat intake and risk of breast cancer among premenopausal women. Arch Intern Med. 2006;166(20):2253-2259.

29. Playdon MC, Ziegler RG, Sampson JN, et al. Nutritional metabolomics and breast cancer risk in a prospective study. Am J Clin Nutr. 2017;106(2):637-649.

30. Marmot M, Atinmo T, Byers T, et al. Food, nutrition, physical activity, and the prevention of cancer: a global perspective. Washington, DC: World Cancer Research Fund/ American Institute for Cancer Research; 2007.

31. Lauby-Secretan B, Scoccianti C, Loomis D, et al.; International Agency for Research on Cancer Handbook Working Group. Body fatness and cancerviewpoint of the IARC Working Group. N Engl J Med. 2016;375(8):794-798.

32. Larsson SC, Mantzoros CS, Wolk A. Diabetes mellitus and risk of breast cancer: a meta-analysis. Int J Cancer. 2007;121(4):856-862.

33. Rangel-Huerta OD, Pastor-Villaescusa B, Gil A. Are we close to defining a metabolomic signature of human obesity? A systematic review of metabolomics studies. Metabolomics. 2019;15(6):1-31.

34. Libert DM, Nowacki AS, Natowicz MR. Metabolomic analysis of obesity, metabolic syndrome, and type 2 diabetes: amino acid and acylcarnitine levels change along a spectrum of metabolic wellness. PeerJ. 2018;6:e5410.

35. Wang TJ, Larson MG, Vasan RS, et al. Metabolite profiles and the risk of developing diabetes. Nat Med. 2011;17(4):448-453.

36. Würtz $P$, Wang $Q$, Kangas AJ, et al. Metabolic signatures of adiposity in young adults: Mendelian randomization analysis and effects of weight change. PLoS Med. 2014;11(12):e1001765.
37. Wang Q Holmes MV, Smith GD, Ala-Korpela M. Genetic support for a causal role of insulin resistance on circulating branched-chain amino acids and inflammation. Diabetes Care. 2017;40(12):1779-1786.

38. Mahendran Y, Jonsson A, Have CT, et al. Genetic evidence of a causal effect of insulin resistance on branched-chain amino acid levels. Diabetologia. 2017; 60(5):873-878.

39. Krebs M, Brunmair B, Brehm A, et al. The mammalian target of rapamycin pathway regulates nutrient-sensitive glucose uptake in man. Diabetes. 2007; 56(6):1600-1607.

40. Tremblay F, Marette A. Amino acid and insulin signaling via the mTOR/ p70 S6 kinase pathway A negative feedback mechanism leading to insulin resistance in skeletal muscle cells. J Biol Chem. 2001;276(41): 38052-38060.

41. Dillon R, White D, Muller W. The phosphatidyl inositol 3-kinase signaling network: implications for human breast cancer. Oncogene. 2007;26(9): 1338-1345.

42. Wishart DS, Jewison T, Guo AC, et al. HMDB 3.0-the human metabolome database in 2013. Nucleic Acids Res. 2013;41(Database issue): D801-D807.2012

43. Townsend MK, Clish CB, Kraft P, et al. Reproducibility of metabolomic profiles among men and women in 2 large cohort studies. Clin Chem. 2013;59(11) 1657-1667.

44. Ghosh S, Sengupta A, Chandra K. Quantitative metabolic profiling of NMR spectral signatures of branched chain amino acids in blood serum. Amino Acids. 2015;47(10):2229-2236.

45. Wolak-Dinsmore J, Gruppen EG, Shalaurova I, et al. A novel NMR-based assay to measure circulating concentrations of branched-chain amino acids: elevation in subjects with type 2 diabetes mellitus and association with carotid intima media thickness. Clin Biochem. 2018;54:92-99. 